\title{
Влияние ступенчатого профиля состава на формирование инверсии в пленках материала кадмий-ртуть-теллур
}

\author{
В.А. Стучинский, А.В. Вишняков, Г.Ю. Сидоров \\ Институт физики полупроводников им. А.В. Ржанова СО РАН, \\ Новосибирск, 630090, пр. Ак. Лаврентьева, 13 \\ тел:+7 (383) 333-2276, факс+7 (383) 333-2276, эл.nочта: stuchin@isp.nsc.ru
}

DOI 10.34077/RCSP2019-149

Варизонные слои $\mathrm{Hg}_{1-x} \mathrm{Cd}_{x} \mathrm{Te}$ (КРТ) используются для пассивации поверхности пленок этого материала в фотоприемниках с целью подавления поверхностной рекомбинации неравновесных носителей заряда. С другой стороны, при наличии в изолирующем диэлектрике заряда наличие широкозонного слоя на поверхности пленок КРТ влияет на условия формирования в системе инверсии, являющейся паразитным фактором с точки зрения работы фотодиодов матрицы. Исследованию влияния профиля состава на формирование инверсии в пленках КРТ было посвящено значительное количество работ (см., например, работу [1] и цитированную в ней литературу). Однако в этих работах при расчете областей пространственного заряда (ОПЗ) в основном анализировался случай профилей состава с плавным спаданием стехиометрического коэффициента $x$ в объем пленки. Такие распределения не позволяют получить ясного представления об обстоятельствах и зависимостях, определяющих влияние параметров варизонных слоев на величину поверхностного инверсионного потенциала полупроводника.

В настоящей работе нами был проанализирован допускающий гораздо более прозрачный анализ модельный случай распределения $x$ в форме ступеньки состава. Рассматривались ситуации, когда инверсия формируется у поверхности либо на границе широкозонного слоя (КРТ-1) и узкозонного КРТ (КРТ-2) p-типа проводимости (случаи относительно узких и относительно широких широкозонных слоев, соответственно).

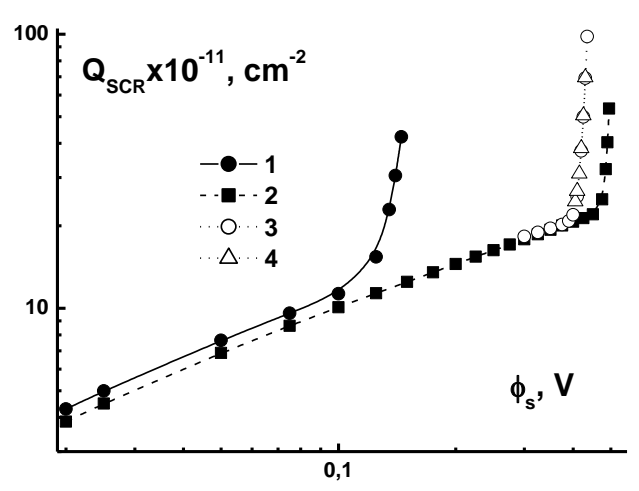

Заряд ОПЗ $Q_{S C R}$ как функция поверхностного потенциала $\varphi_{s}$ : кривые 1 и 2 - однородный КРТ состава $x=0.22$ и 0.45 , соответственно; кривые 3 и 4 ступенька между указанными составами, расположенная на глубинах $2 \cdot 10^{-5}$ и $3 \cdot 10^{-5}$ мкм.

Рассмотрим для примера первый случай. При одинаковом уровне легирования различие величин электронного сродства и ширины запрещенной зоны КРТ-1 и КРТ-2 приводит к различию уровней Ферми в двух материалах и к разрыву краев зон для электронов и дырок на контактной границе (величиной $\Delta_{n}$ и $\Delta_{p}$, соответственно). При контактировании в условиях квазинейтрального объема (КО) выравнивание уровней Ферми между двумя материалами осуществляется в основном благодаря перетеканию части дырок из КРТ-1 в КРТ-2 с образованием на контактной границе двойного заряженного слоя. Величина поверхностного потенциала для формирования инверсии $\varphi_{i n v}$ определяется при увеличения величины поверхностного потенциала $\varphi_{s}$ до появления в системе инверсии, и здесь возможны два случая: когда контакт между КРТ-1 и КРТ-2 на момент формирования инверсии находится в области обеднения и когда этот контакт находится в КО полупроводника. Во втором случае двойной заряженный слой исчезает с восстановлением разрыва края валентной зоны, в первом же случае такого восстановления не происходит (ввиду большого значения длины Дебая по сравнению с толщиной слоя КРТ-1). Нетрудно видеть поэтому, что величина $\varphi_{i n v}$ должна отличаться от потенциала инверсии узкозонного полупроводника (когда вся система образована узкозонным материалом КРТ-2) на величину $\Delta_{n}$ и $\Delta_{n}+\Delta_{p}$ (первый и второй случай, соответственно). Аналогичным образом может быть проанализирован случай, когда инверсия в системе возникает на границе между материалами КРТ-1 и КРТ-2.

Выявленные закономерности были подтверждены численными расчетами, основанными на решении нелинейного уравнения Пуассона для рассматриваемой системы (см. рисунок). Также было изучено влияние параметров системы на формирование в ней инверсии. Полученные данные могут быть полезны при выборе оптимальных параметров варизонных слоев в фоточувствительных пленках КРТ-фотоприемников.

\section{Литература}

[1] А.В. Предеин, В.В. Васильев // Прикладная физика. 2011. №35. С.41-47. 